\title{
Phytocontact dermatitis due to Mentha rotundifolia: A case report
}

\section{Ouiam El Anzi, Asmae Sqalli, Safae Maouni, Karima Senouci, Badredine Hassam}

Department of Dermatology-Venereology, Ibn Sina University Hospital, Mohammed V University, Rabat, Morocco

Corresponding author: Dr. Ouiam El Anzi, E-mail: elanzi.ouiam@gmail.com

Sir.,

Phytodermatoses are skin lesions secondary to prolonged contact with bound herbs. Many plants are represented liable for this kind of incident [1].

We present a case of phytocontact dermatitis associated with the use of a plant mimicking burn injury.

A 38-year-old female patient, without pathological history, presented to the consultation with complaints of vesiculous lesions at the lumber region (Fig. 1). The questioning found the application 2 days ago of a poultice for 6 hours containing the "Mentha rotundifolia" to treat low back pain.

Dermatological examination revealed a second degree burn. The care provided helped a favorable evolution in few days.

Many modern drugs owe their origin to plant-based complementary medicine, and there has been an upsurge of interest in the potential use of medicinal plants for the treatment of a wide range of disorders [2] . In Morocco, it is well known that many alternative herbal remedies are used for different indications, especially for rheumatological joint pain.

The adverse effects of plants on skin are typically manifest via 3 main mechanisms: irritant, phototoxic, and hypersensitivity reactions [3].

Mentha rotundifolia (Fig. 2) also called Mentha suaveolens or apple mint belongs to Lamiaceae family is found along rivers in plains and mountains.

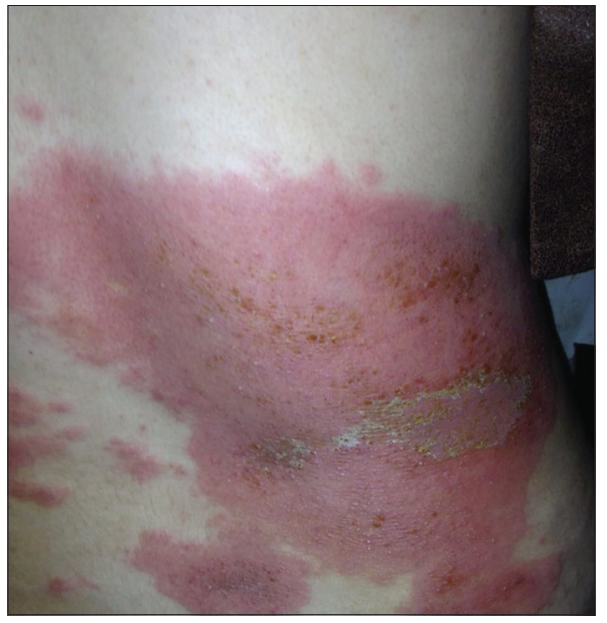

Figure 1: Vesiculo-erythematous lesions at the lumber region.

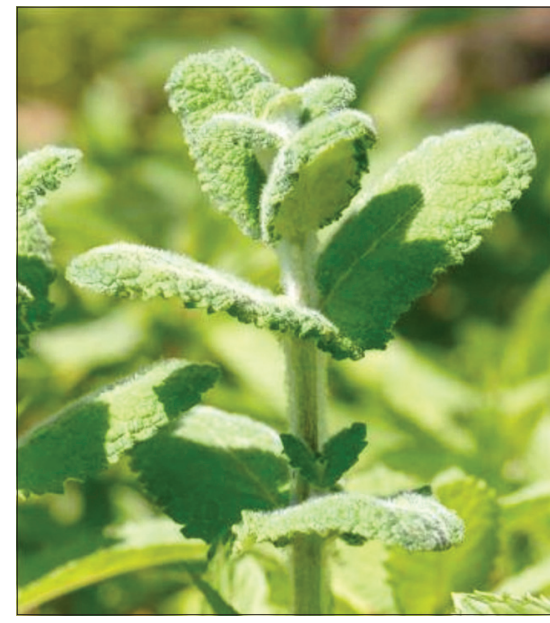

Figure 2: Mentha rotundifolia.

It is a perennial plant that blooms in spring and summer under the semi-arid cold and subhumid Mediterranean bioclimate [4].

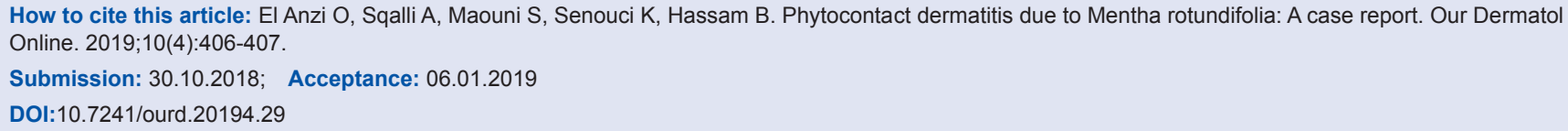


Features oblong to ovate light green leave and terminal spikes of small pink to white flowers in summer.

Leaves have a fruity fragrance and taste.

It is gently used in herbal medicine for her virtues tonic, antispasmodic, antipyretic, stimulating and even for culinary purposes.

In our case, use for antalgic purposes has caused a chemical burn of the second degree. There is a phytodermatose described only once to our knowledge.

Although plant poultices applied to the skin show positive effects on many rheumatic and dermatological diseases, they even have several adverse effects [5]. We believe that benefiting from modern medicine is the correct approach rather than attempting alternative treatment methods, whose therapeutic effects have not been proven yet by scientific studies.

\section{Consent}

The examination of the patient was conducted according to the Declaration of Helsinki principles.

\section{REFERENCES}

1. El Makrini N, Hassam B. Artemisia absinthium: burning plant! Pan Afr Med J. 2016;23:10.

2. Mantle D, Gok MA, Lennard TWC. Adverse and beneficial effects of plant extracts on skin and skin disorders. Adverse Drug React Toxicol Rev. 2001:20:89-103.

3. Polat M, Oztas P, Yalcin B, Tamer E, Gur G, Alli N. Contact dermatitis due to Allivum sativum and Ranunculus illyricus: two cases. Contact Dermatitis. 2007;57:279-80.

4. Benhiba H, Hassam B. [Phytophotodermatitis due to Mentha rotundifolia]. Pan Afr Med J. 2014;18:192.

5. Akbulut S, Semur H, Kose O, Ozhasenekler A, Celiktas M, Basbug M, et al. Phytocontact dermatitis due to Ranunculus arvensis mimicking burn injury: report of three cases and literature review. Int J Emerg Med. 2011;4:7.

Copyright by Ouiam El Anzi, et al. This is an open-access article distributed under the terms of the Creative Commons Attribution License, which permits unrestricted use, distribution, and reproduction in any medium, provided the original author and source are credited.

Source of Support: Nil, Conflict of Interest: None declared. 